\title{
RESENHA \\ Carlos Guido y Spano (1827-1918)
}

Márcio Bobik Braga(*)

Carlos Guido y Spano foi um dos principais poetas da Literatura Argentina. Nascido em Buenos Aires, foi filho do General Tomás Guido, que lutou ao lado de San Martín pela independência da América Espanhola. Viveu a sua adolescência no Rio de Janeiro, cidade que talvez tenha tido papel fundamental no desenvolvimento da sua sensibilidade artística, conforme sugere o trecho presente em sua autobiografia, publicada originalmente em 1874: "Llego a Río de Janeiro. ¡Salve, románticas montanas, ondas apacibles, islas pintorescas donde durante la friolera de unos diez anos, corriendo la gandaya, debía deliciosamente holgazanear! ¡Si fuera yo pintor! ¿Mas qué pincel pudiera reproducir la agreste hermosura del paisaje, el verde y fresco panorama que se te presenta a la vista?". No mesmo texto também escreve sobre a vida cotidiana na cidade carioca: "A más, andando el tiempo, y rayando ya en la juventud, de vuelta de mis excursiones montesinas, frecuentaba yo la mejor sociedad, de que era núcleo principal el salón de mi madre, asistiendo con frecuencia a las tertulias, los bailes, los espectáculos públicos. Empero, a todo prefería el ir a divagar solitario el fondo de las misteriosas florestas". Além de seu amor pela arte e talvez pela sua sensibilidade poética, Guido y Spano não pode ficar distante dos conflitos políticos na Argentina de sua época. Fez parte de uma geração de intelectuais que procurou denunciar os prejuízos humanos da Guerra do Paraguai e que mudaria a história dos países que dela participaram. O poema Nenia mistura beleza com profunda tristeza nessa denúncia. Guido y Spano produziu outros textos, principalmente na imprensa de Buenos Aires, denunciando os políticos responsáveis pela guerra que destruiu uma sociedade latino-americana.

\section{Bibliografia}

GUIDO Y SPANO, Carlos. Autobiografía ou Carta confidencial a un amigo que comete la indiscreción de publicarla, publicada originalmente em 1879, reproduzido em Prosa y Poesía de Guido Spano, Editorial Universitaria de Buenos Aires (prólogo de Fermín Estrella Gutiérez), Buenos Aires, 1964. SHUMWAY, Nicolas. A Invenção da Argentina. Editora Edusp/Editora da UNB, 2008.

$\left({ }^{*}\right)$ Professor do Departamento de Economia da USP do campus de Ribeirão Preto e do Programa de Pós-Graduação em Integração da América Latina — PROLAM/USP. 
NENIA $^{(1)}$

Llora, llora urutaú

En idioma guaraní

una joven paraguaya

tiernas endechas ensaya

cantando en el harpa así,

en idioma guaraní:

¡Loora, llora ûrutaú(2)

en las ramas del yatay ${ }^{(3)}$,

ya no existe el Paraguay

donde nací como tú -

lora, llora, ûrutaú!

En el dulce Lambaré

feliz era en mi cabaña

vino la guerra y su saña

no ha dejado nada en pie

En el dulce Lambaré!

¡Padre, madre, hermanos! ¡Ay!

Todo en el mundo he perdido;

en mi corazón partido

solo amargas penas hay -

¡Padre, madre, hermanos! ¡Ay!

De un verde ubirapitá

mi novio que combatió como un héroe en el Timbó,

al pie sepultado está

de un verde ubirapitá!

Rasgado el blanco tipoy ${ }^{(4)}$

tengo en señal de mi duelo,

y en aquel sagrado suelo

de rodillas siempre estoy,

rasgado el blanco tipoy.

Lo mataron los cambá

no pudiéndole rendir;

él fue el último en salir

de Curuçú y Humaitá

¡Lo mataron los cambá!

¡Por qué, cielos, no morí

cuando me estrechó triunfante

entre sus brazos mi amante

después de Curupaití!

¡Por qué, cielos, no morí!...

¡Loora, llora ûrutaú

en las ramas del yatay;

ya no existe el Paraguay

donde nací como tú -

lora, llora, ûrutaú!

\footnotetext{
(1) Nenia: canción fúnebre.

(2) Ûrutaú: um pássaro da região.

(3) Yatay: uma palmeira.

(4) Tipoy: uma saia usada pelas mulheres paraguaias.
} 


\section{Revista Cadernos PROLAM/USP \\ Brazilian Journal of Latin American Studies}

\section{Normas de Editoriais}

\section{Foco e Escopo}

1. De acordo com a política editorial adotada pela revista, somente serão analisados, para eventual publicação, artigos, resenhas, documentos e ensaios de conteúdo inédito, tanto no país quanto no exterior. Esses textos são aqui genericamente designados "artigos" ou "artigo". Além disso, o conteúdo do artigo deverá estar claramente relacionado com o tema da Integração Latino-Americana, podendo adotar diferentes perspectivas, tais como a social, política, econômica, jurídica, histórica, cultural, artística, de comunicação social. Espera-se que o artigo contribua de modo significativo ao avanço do conhecimento científico no tema da integração latino-americana.

2. Resenhas de livros recentemente publicados poderão ser consideradas para publicação, mas, de modo geral, não serão aceitas resenhas temáticas e textos essencialmente descritivos.

3. Os autores dos artigos aprovados não serão remunerados a qualquer título. A eventual publicação do artigo na revista implicará na automática transferência dos direitos autorais ao Prolam/USP. A aprovação do artigo para publicação na versão impressa da revista abrange também sua eventual publicação em mídia digital e sua inserção nos sistemas de bibliotecas da USP.

4. O artigo submetido à revista para análise deverá ser escrito em português, inglês ou espanhol e, caso seja aprovado, será aplicado no idioma em que tiver sido submetido para análise.

5. Anexos muito longos ou complexos para serem publicados, bem como as bases de dados necessárias para reproduzir os resultados empíricos do trabalho, serão oferecidos aos leitores em versão virtual.

6. Caso o artigo seja aceito para publicação, seu autor receberá 3 (três) exemplares do número da revista correspondente.

7. Os artigos submetidos à revista para análise serão avaliados pelo Corpo Editorial, com o auxílio de dois consultores ad hoc que serão escolhidos pelo Editor. As atividades dos consultores ad hoc são realizadas de forma duplamente anônima: o autor não saberá quem são os consultores ad hoc, nem eles quem é o autor. Dessa análise poderá resultar a aceitação do artigo, condicionada, ou não, à realização de alterações pelo respectivo autor; a sua rejeição, com ou sem a recomendação de nova submissão depois de modificações; ou a sua rejeição definitiva. No caso de uma segunda submissão, a rotina de análise se repetirá até que uma decisão final de rejeição ou aceitação seja alcançada. O processamento do artigo é conduzido pelo Editor, a quem compete a comunicação com o respectivo autor.

8. A decisão final quanto à publicação dos artigos cabe ao Corpo Editorial, que se reúne ordinariamente para decidir a composição de cada um dos números da revista, por recomendação do Editor. A aprovação do artigo para publicação será comunicada por escrito ao seu autor. 


\section{Limitação de Responsabilidades}

As opiniões, interpretações e análises contidas em cada artigo publicado são de exclusiva e inteira responsabilidade dos respectivos autores, não exprimindo, necessariamente, o ponto de vista do Prolam/USP.

\section{Termos de Uso}

É permitida a cópia, reprodução e distribuição de textos, imagens, dados e demais arquivos, no todo ou em parte, em qualquer formato ou meio, desde que sejam observadas as seguinte regras:

a. O uso do material copiado deve se destinar apenas a fins educacionais, de pesquisa, uso pessoal, circulação interna ou outros usos não comerciais. Reprodução para fins comerciais são proibidas;

b. O material deve ser reproduzido sem sofrer qualquer alteração ou edição de conteúdo em relação ao original;

c. A reprodução deverá ser acompanhada da citação da fonte, no seguinte formato: Fonte: Revista Cadernos Prolam/USP. Brazilian Journal of Latin American Studies; e

d. Os nomes e endereços informados na revista serão usados exclusivamente para os serviços prestados por esta publicação, não sendo disponibilizados para outras finalidades ou a terceiros.

\section{Diretrizes para Autores}

Para submeter um artigo à revista, o autor deverá fornecer o texto em formato digital, como um arquivo produzido pelo programa Microsoft Office Word. Gráficos devem ser enviados em arquivo separado. Cada autor deverá se identificar com nome, endereço eletrônico, titulação, instituição a que pertence, localidade e país. O texto contido no arquivo deverá observar as seguintes normas:

a. O texto deverá ser digitado com o tipo Times New Roman de corpo 12, com espaçamento 1,5 entre linhas. As margens esquerda, direita, superior e inferior, de cada lauda, deverão ser de $3 \mathrm{~cm}$.

b. Os artigos deverão ter, no máximo, 25 laudas, e as resenhas bibliográficas não deverão ultrapassar 10 laudas.

c. O artigo, escrito em português, espanhol ou inglês, deverá ser apresentado com título em português e inglês e com um resumo de cerca de 100 palavras - em português e em inglês - que ofereça visão sumária do seu objetivo, metodologia empregada e dos principais resultados alcançados.

d. Os gráficos, mapas e outros elementos gráficos deverão ser apresentados na forma de arte-final, sendo sua nitidez requisito indispensável para eventual aceitação do artigo para publicação.

e. Equações matemáticas deverão ser alinhadas à esquerda e numeradas sequencialmente à direita. Deverão ser digitadas no próprio texto com o uso do processador de equações do Microsoft Office Word. Deverá ser utilizada a convenção-padrão daquele 
programa para formatação dos diferentes tipos de entidades que aparecem nas equações (símbolos matemáticos, texto, vetores etc.). Quando a derivação delas for apresentada de modo sintético, o autor fornecerá a derivação completa em anexo, para facilitar as atividades dos consultores ad hoc e do Corpo Editorial.

f. A referência completa de todos os textos citados deverá ser apresentada no fim do artigo, em ordem alfabética, conforme indica a Associação Brasileira de Normas Técnicas/ABNT por meio da NBR 6023, contendo: no caso de livros - nome completo do autor, título completo, nome e número da série ou coleção (se houver), edição, local, editora, ano da publicação; e, no caso de artigos de periódicos - nome completo do autor, título completo do artigo, título completo do periódico, local, número das páginas, mês e ano da publicação.

Exemplo:

HICKS, John Richard. Value and capital. Oxford: Clarendon Press, 1974.

HICKS, John Richard. Mr. Keynes and the "classics": a suggested interpretation. Econometrica, v. 5, n. 3, p. 147-155, abr. 1937.

HICKS, John Richard. Ricardo's theory of distribution. In: PESTON, MAURICE HARRY; CORRY, BERNARD. (Eds.). Essays in honour of Lord Robbins. London: Weidelfeld, 1972.

g. As notas de rodapé deverão ser numeradas sequencialmente, digitadas em tipo Times New Roman de corpo 10, com espaçamento 1 entre linhas, e deverão ser utilizadas parcimoniosamente.

h. As citações bibliográficas deverão ser incluídas no próprio texto e devem aparecer como indica a Associação Brasileira de Normas Técnicas/ABNT por meio da NBR 10520, por exemplo, ao formato "Hicks (1939)" ou "Hicks (1939, p. 36-37)" ou "(HICKS, 1939, p. 36-37)".

i. As tabelas deverão ter título, ser numeradas sequencialmente e todas as colunas e linhas rotuladas. Deverão ser digitadas no tipo Arial de corpo 9, com espaçamento 1 entre linhas.

\section{Itens de Verificação para Submissão}

Os examinadores designados para a análise do artigo submetido à revista verificarão se o texto preenche os requisitos formais e materiais acima mencionados e também verificarão se:

1. A contribuição é original, inédita e não está sendo avaliada para publicação por outra revista. O examinador justificará sua manifestação em "Comentários ao Editor".

2. Todos os endereços de páginas na Internet (URLs), incluídos no texto (Ex.: http://www.ibict.br), estão ativos e prontos para acesso.

3. O texto emprega itálico em vez de sublinhado (exceto em endereços URL); com figuras e tabelas inseridas no corpo do texto e não em seu final.

Serão devolvidos aos autores os artigos que não estiverem de acordo com as normas aqui estabelecidas. 


\section{Agradecimentos}

O Conselho Editorial da Revista Cadernos PROLAM/USP agradece aos colaboradores que participaram como pareceristas nas edições de 2009:

Amaury Patrick Gremaud

Elizabeth Balbachevsky

Fausto Saretta

Gladys Beatriz Barreyro

Luiz Antonio Lindo

Márcio Bobik Braga

Maria Cristina Cacciamali

Osvaldo Coggiola

Renato Seixas

Shiguenoli Miyamoto

Umberto Celli Júnior

Vivian Grace Fernandez Dávila Urquidi

Wagner Menezes

Endereço PROLAM/USP

Rua do Anfiteatro, 181 - Colmeias - Favo 1 CEP: 05508-060 - Cidade Universitária/SP Fone/Fax: 3091-3589 / 3091-3587 / 3815-0167 prolam@usp.br www.usp.br/prolam 
